\title{
Danish Colorectal Cancer Group Database
}

This article was published in the following Dove Press journal:

Clinical Epidemiology

25 October 2016

Number of times this article has been viewed

\author{
Peter Ingeholm ${ }^{1,2}$ \\ Ismail Gögenur ${ }^{1,3}$ \\ Lene $\mathrm{H}$ Iversen ${ }^{1,4}$ \\ 'Danish Colorectal Cancer Group \\ Database, Copenhagen, ${ }^{2}$ Department \\ of Pathology, Herlev University \\ Hospital, Herlev, ${ }^{3}$ Department of \\ Surgery, Roskilde University Hospital, \\ Roskilde, ${ }^{4}$ Department of Surgery P, \\ Aarhus University Hospital, Aarhus C, \\ Denmark
}

Correspondence: Peter Ingeholm Department of Pathology, Herlev University Hospital, Herlev Ringvej 75,

DK 2730 Herlev, Denmark

Tel +453868 | 403

Fax +45 3868 37II

Email peter.ingeholm.0I@regionh.dk
Aim of database: The aim of the database, which has existed for registration of all patients with colorectal cancer in Denmark since 2001, is to improve the prognosis for this patient group.

Study population: All Danish patients with newly diagnosed colorectal cancer who are either diagnosed or treated in a surgical department of a public Danish hospital.

Main variables: The database comprises an array of surgical, radiological, oncological, and pathological variables. The surgeons record data such as diagnostics performed, including type and results of radiological examinations, lifestyle factors, comorbidity and performance, treatment including the surgical procedure, urgency of surgery, and intra- and postoperative complications within 30 days after surgery. The pathologists record data such as tumor type, number of lymph nodes and metastatic lymph nodes, surgical margin status, and other pathological risk factors.

Descriptive data: The database has had $>95 \%$ completeness in including patients with colorectal adenocarcinoma with $>54,000$ patients registered so far with approximately one-third rectal cancers and two-third colon cancers and an overrepresentation of men among rectal cancer patients. The stage distribution has been more or less constant until 2014 with a tendency toward a lower rate of stage IV and higher rate of stage I after introduction of the national screening program in 2014. The 30-day mortality rate after elective surgery has been reduced from $>7 \%$ in 2001-2003 to $<2 \%$ since 2013.

Conclusion: The database is a national population-based clinical database with high patient and data completeness for the perioperative period. The resolution of data is high for description of the patient at the time of diagnosis, including comorbidities, and for characterizing diagnosis, surgical interventions, and short-term outcomes. The database does not have high-resolution oncological data and does not register recurrences after primary surgery. The Danish Colorectal Cancer Group provides high-quality data and has been documenting an increase in short- and long-term survivals since it started in 2001 for both patients with colon and rectal cancers.

Keywords: clinical quality database, quality indicator, disease register, colon neoplasms, rectal neoplasms

\section{Aim of database}

The Danish Colorectal Cancer Group (DCCG) is a subgroup of the Danish Surgical Society. In 1994, DCCG founded a national database with the aim to improve the quality of the diagnostic workup and treatment of Danish patients with rectal cancer. Since May 2001, the database has also included all Danish patients with colon cancer. ${ }^{1}$ In 2006, DCCG became a multidisciplinary cancer group under the auspices of the Danish Multidisciplinary Cancer Group (DMCG.dk), ${ }^{2}$ with participation of the following specialties: surgery, radiology, oncology, and pathology. Until 2009, only the 
surgeons entered data into the database, but since the end of 2009 , the pathologists have also entered data into the database. From the end of 2009 to 2013, the oncologists entered data manually by registering pre- and postoperative start of oncological treatment, but due to low data completeness, this was abandoned by the end of 2014 .

The aim of the database is to improve the prognosis for the Danish patients with colorectal cancer by the following: 1) standardizing and improving the diagnostic workup of the patients with colorectal cancer, 2) standardizing and improving the surgical and oncological treatments, and 3) standardizing and improving the follow-up of the patients. This is achieved by monitoring the clinical quality indicators, which are published in annual reports, at department, regional, and national levels. Clinical quality indicators used in 2014 are shown in Table 1. The individual departments can monitor their own performance and extract their own data from the database, thus enabling local auditing of performance.

\section{Study population}

The database of the study population is all Danish citizens aged at least 18 years, diagnosed with primary colorectal cancer from May 2001 and onward, and diagnosed and/or treated at a surgical department at a public Danish hospital. Only patients with primary adenocarcinoma, mucinous adenocarcinoma, signet ring cell carcinoma, medullary carcinoma, or undifferentiated carcinoma are included. Patients with metachronous colorectal cancer are not included, and data on recurrent disease are not recorded.

Every person in Denmark is registered at birth by a unique identification number in the Central Civil Registration Registry. ${ }^{3}$ This number is also used by health registries, other health authorities (eg, the National Patient Registry ${ }^{4,5}$ and the Cause of Death Registry ${ }^{6}$ ), and the DCCG database giving the opportunity to have a virtually complete registration and follow-up in all contacts to the health system.

Since 2010, the patient completeness (the rate of patients with a surgical registration to all patients identified in the central registries) has been $99 \%$, and previously, $>95 \%$. To achieve such patient completeness based on the searches for patients with colorectal cancer in the National Patient Registry,

Table I Data sources

\begin{tabular}{ll}
\hline Manual registration & Online web-based database \\
\hline Central registries & The Danish Cancer Registry \\
& National Patient Registry (LPR) \\
& The Central Civil Registration Registry (CPR) \\
& The Danish Pathology Registry (from 2016) \\
\hline
\end{tabular}

the database provides lists to the surgical and pathology departments of patients who are not yet recorded in the database.

Since the DCCG database does not include metachronous cancer and recurrences, it does not provide a complete picture of all the patients with colorectal cancer. In addition, there may be a small proportion of patients who were not included in the database. These include patients where a diagnosis of colorectal cancer is based on a death certificate only, or who have not been admitted to a surgical department, or for whom no biopsy exists. This proportion is believed to be very limited.

\section{Main variables}

As of June 8, 2015, the database included 54,326 patients $(35,922$ with colon cancer and 18,404 with rectal cancer) with a completed surgical proforma. For 19,266 of these patients, the database also includes pathology data.

The database comprises a number of clinical, surgical, radiological, and pathological variables. The database uses an array of different data sources, the most important being a web-based proforma with manual online recording in a surgical and pathology proforma by the colorectal cancer surgeons and pathologists, respectively. The other data sources are listed in Table 2.

The surgeons record data about the patient lifestyle and comorbidity, performance, American Society of Anesthesiologists score, ${ }^{7}$ height, weight, and results of the clinical examination including radiology, bowel cancer screening, and multidisciplinary team meetings. Variables regarding preoperative surgical and/or oncological treatment, the primary surgical procedure, operative details such as blood loss, division of tumor feeding arteries, tumor location, and operative approach, such as the type of intraoperative complications and postoperative surgical and nonsurgical complications, occurring within 30 days postoperatively, are also recorded.

Table 2 Overview of clinical quality indicators and their standards (\%) in 2014

\begin{tabular}{ll}
\hline Name & $\begin{array}{l}\text { Standard } \\
(\%)\end{array}$ \\
\hline MDT conference in patients with a newly diagnosed rectal & $>90$ \\
cancer & $>25$ \\
Extramural venous invasion & $<10$ \\
Anastomotic leakage after rectal cancer surgery & $<3$ \\
Postoperative death after elective surgery & $>90$ \\
Radicality after elective surgery & $>90$ \\
Specialist surgeon performing emergency colonic cancer & $>90$ \\
surgery & $<7$ \\
Specialist surgeon performing elective colonic cancer surgery & $>90$ \\
Anastomotic leakage after colonic cancer surgery & \\
\hline Abbreviation: MDT, multidisciplinary team. &
\end{tabular}

Clinical Epidemiology 2016:8 
Since 2014, the postoperative complications have been graded according to the Clavien-Dindo classification. ${ }^{8,9}$

The data set also includes a number of other important disease characteristics most important being variables about tumor stage according to Union for International Cancer Control and pTNM stage. ${ }^{10}$ The Union for International Cancer Control stage is calculated using an algorithm involving data from both the surgical and the pathology proforma. Other variables are age, age group, and sex. The database calculates a Charlson comorbidity index ${ }^{11}$ based on the data from the National Patient Registry using an algorithm used by the Danish Multidisciplinary Cancer Group (DMCG. dk). ${ }^{2}$ Other descriptive variables are 30-day postoperative mortality and overall survival using data from the Central Civil Registration Registry. ${ }^{3}$

The pathologists record data regarding the local excision specimens and the resection specimens (Table 3 ). The pathology proforma includes variables such as histology including results of immunohistochemical staining for expression of mismatch repair proteins, tumor regression after neoadjuvant chemo- or radio- or chemoradiotherapy, surgical margin status, risk factors, such as tumor perforation, serosal involvement, venous invasion, and perineural spread, morphometric data, number of examined nodes and metastases, and the quality of the resection specimens. The $\mathrm{pT}, \mathrm{pN}$, and $\mathrm{pV}$ stages are calculated from the raw data entered into the pathology proforma. The key variables have been listed in Table 3.

Due to poor data completeness regarding oncological data about adjuvant chemotherapy, the steering committee of the database has decided to abandon manual registration by the oncologists in 2014. In the future, the database will capture data about oncological treatment of the patients with colorectal cancer from the National Patient Registry. From 2016, the pathology data will come from The Danish Pathology Registry, and the pathologists will no longer need to enter the data manually.

The surgical proforma was upgraded in 2014 where new variables were introduced, variables were defined, and a number of old variables were excluded from the database. The proforma will undergo an annual revision in order to adapt to new diagnostic and treatment options. The database has planned a separate proforma to monitor the implementation of a new surgical procedure, transanal minimally invasive surgery.

\section{Follow-up}

The registration in the database does not include registration of clinical follow-up data besides survival of the patients. Thus, the database does not record follow-up data, such as local or distant recurrence, functional outcome, or quality of
Table 3 Registered variables

\begin{tabular}{|c|c|}
\hline Section & Key variables \\
\hline $\begin{array}{l}\text { Initial contact and } \\
\text { treatment plan }\end{array}$ & $\begin{array}{l}\text { Date of diagnosis, bowel cancer screening, surgical } \\
\text { treatment, reason for abstaining from surgery, and } \\
\text { discussion at an MDT meeting }\end{array}$ \\
\hline $\begin{array}{l}\text { Patient } \\
\text { characteristics }\end{array}$ & $\begin{array}{l}\text { Height, weight, WHO performance, ASA score, } \\
\text { use of tobacco and alcohol consumption, and } \\
\text { hereditary colorectal cancer }\end{array}$ \\
\hline Radiology & Type and result of radiological examination used \\
\hline $\begin{array}{l}\text { Preoperative } \\
\text { treatment }\end{array}$ & $\begin{array}{l}\text { Bridge-to-surgery procedures, type of neoadjuvant } \\
\text { therapy, and surgery for metastases }\end{array}$ \\
\hline Operation & $\begin{array}{l}\text { Date of operation, level of surgeons' education, } \\
\text { type of operation, surgical intent, urgency of surgery, } \\
\text { operative approach, and various surgical details } \\
\text { (supplemental resections, stoma, anastomotic } \\
\text { details, blood loss, tumor perforation, etc) }\end{array}$ \\
\hline $\begin{array}{l}\text { Surgical } \\
\text { complications }\end{array}$ & $\begin{array}{l}\text { Intraoperative complications and postoperative } \\
\text { surgical ( } \leq 30 \text { days postoperatively) and medical } \\
\text { complications ( } \leq 30 \text { days postoperatively) graded } \\
\text { am Clavien-Dindo }\end{array}$ \\
\hline Follow-up & Date of death \\
\hline Tumor stage & TNM and UICC stages \\
\hline Pathology & $\begin{array}{l}\text { Tumor histology and MMR protein expression, } \\
\text { various risk factors (venous invasion, serosal } \\
\text { involvement, perineural invasion, and tumor } \\
\text { perforation), number of examined lymph nodes and } \\
\text { metastases, and surgical margin status }\end{array}$ \\
\hline
\end{tabular}

Abbreviations: ASA, American Society of Anesthesiologists; MDT, multidisciplinary team; MMR, mismatch repair; TNM, tumor node metastasis; UICC, Union for International Cancer Control; WHO, World Health Organization.

life. Some clinical data might, however, be obtained by linkages to other relevant registries as described earlier.

\section{Examples of research}

The database provides data to researchers and research groups after a formal application to the database and after evaluation by the DCCG's Scientific Committee. The database has seen an increasing demand for its data, with $\sim 20$ data sets provided to researchers in 2014. The database has provided data to $>70$ publications and scientific reports as described in the annual reports. ${ }^{12}$ In 2014, the database undertook to analyze survival of Danish patients with colorectal cancer, as part of a scientific report published by the Danish Multidisciplinary Cancer Group (DMCG.dk) Benchmarking Consortium. ${ }^{13}$

Examples of research based on data from the database are many. Noteworthy is the paper by Andersen et al on intraoperative lesions of the ureter ${ }^{14}$ and a number of important papers by Krarup et $\mathrm{al}^{15,16}$ and Bertelsen et al ${ }^{17}$ regarding anastomotic leakage, which is an area of focus in the database. The database has two quality indicators, regarding anastomotic leakage in both rectal and colon cancer surgery. Another important publication based on data from the database is the publication by Bülow et al on intraoperative perforation of rectal cancer tumors. ${ }^{18}$ Another 
focus area for the database is emergency surgery, where the risk of postoperative death is $>20 \%$. Iversen et al have analyzed various risk factors for postoperative death. ${ }^{19,20}$

\section{Administrative issues and funding}

The database has a steering committee with a chairman appointed by the board of the DCCG. The database is funded by the Danish Regions ${ }^{21}$ and administered by the Danish Clinical Registries (RKKP). ${ }^{22}$ RKKP administers all national cancer databases in Denmark, including the DCCG.

\section{Conclusion}

The DCCG database is a national database covering all newly diagnosed patients with colorectal cancer, with $>95 \%$ patient and data completeness. The database has an important positive impact on the quality of colorectal cancer treatment in Denmark by monitoring an array of clinical quality indicators, such as postoperative mortality, lymph node yield, and anastomotic leakage. In the near future, the database will undertake to monitor new diagnostic and treatment modalities. The database feeds data to an increasing number of researchers, providing important results and information about colorectal cancer treatment in Denmark, as was done regarding the benchmarking report on survival after colorectal cancer in Denmark. ${ }^{13}$

\section{Acknowledgment}

This paper was funded by the Program for Clinical Research Infrastructure established by the Lundbeck Foundation and the Novo Nordisk Foundation and administered by the Danish Regions.

\section{Disclosure}

The authors report no conflicts of interest in this work.

\section{References}

1. Iversen LH. Aspects of survival from colorectal cancer in Denmark. Dan Med J. 2012;59:B4428.

2. DMCG.dk [homepage on the Internet]. Danish Multidisciplinary Cancer Groups. Available from: http://dmcg.dk/. Accessed December 27, 2015.

3. Pedersen CB. The Danish Civil Registration System. Scand J Public Health. 2011;39:22-25.

Clinical Epidemiology

\section{Publish your work in this journal}

Clinical Epidemiology is an international, peer-reviewed, open access, online journal focusing on disease and drug epidemiology, identification of risk factors and screening procedures to develop optimal preventative initiatives and programs. Specific topics include: diagnosis, prognosis, treatment, screening, prevention, risk factor modification, Submit your manuscript here: http://www.dovepress.com/clinical-epidemiology-journal
4. Statens Serum Institut. [homepage on the Internet]. Available from: http://www.ssi.dk/English.aspx. Accessed January 3, 2016.

5. Lynge E, Sandegaard JL, Rebolj M. The Danish National Patient Register. Scand J Public Health. 2011;39(7 suppl):30-33.

6. Juel K, Helweg-Larsen K. The Danish registers of cause of death. Dan Med Bull. 1999;46(4):354-357.

7. Dripps RD. New classification of physical status. Anesthesiol. 1963;24:111.

8. Dindo D, Demartines N, Clavien P. Classification of surgical complications. Ann Surg. 2004;240(2):205-213.

9. Clavien PA, Barkun J, de Oliveira ML, et al. The Clavien-Dindo classification of surgical complications: five-year experience. Ann Surg. 2009;250(2):187-196.

10. Fleming ID, Cooper JS, Henson DE, et al., editors. American Joint Committee on Cancer (AJCC). AJCC Cancer Staging Manual. 5th ed. Philadelphia, PA: J. B. Lippincott; 1997.

11. Charlson ME, Pompei P, Ales KL, MacKenzie CR. A new method of classifying prognostic comorbidity in longitudinal studies: development and validation. J Chronic Dis. 1987;40(5):373-383.

12. DCCG Annual Report 2014 [homepage on the Internet]. Danish Colorectal Cancer Group. Available from: http://www.dccg.dk/pdf/ Aarsrapport_2014.pdf. Accessed January 3, 2016.

13. DMCG.dk Benchmarking Consortium [homepage on the Internet]. Kapitel 3: Tyktarm- og endetarmkræft. Danske Multidisciplinære Cancer Grupper (DMCG.dk) Danish Colorectal Cancer Group (DCCG). Available from: $\mathrm{http} / / / \mathrm{dmcg} . \mathrm{dk} /$ fileadmin/dmcg.dk/Benchmarking_Consortium/D_Colorektal_07_11_2014_v2.pdf. Accessed January 3, 2016.

14. Andersen P, Andersen LM, Iversen LH. Iatrogenic ureteral injury in colorectal cancer surgery: a nationwide study comparing laparoscopic and open approaches. Surg Endosc. 2015;29(6):1406-1412.

15. Krarup P, Nordholm-Carstensen A, Jorgensen LN, Harling H. Anastomotic leak increases distant recurrence and long-term mortality after curative resection for colonic cancer: a nationwide cohort study. Ann Surg. 2014;259(5):930-938.

16. Krarup PM, Jorgensen LN, Harling H. Management of anastomotic leakage in a nationwide cohort of colonic cancer patients. $\mathrm{J} \mathrm{Am} \mathrm{Coll}$ Surg. 2014;218(5):940-949.

17. Bertelsen CA, Andreasen AH, Jorgensen T, Harling H. Anastomotic leakage after anterior resection for rectal cancer: risk factors. Colorectal Dis. 2010;12(1):37-43.

18. Bülow S, Christensen IJ, Harling H, Kronborg O, Fenger C, Nielsen HJ. Recurrence and survival after mesorectal excision for rectal cancer. $\mathrm{Br} J$ Surg. 2003;90(8):974-980.

19. Iversen LH, Ingeholm P, GöGenur I, Laurberg S. Major reduction in 30-day mortality after elective colorectal cancer surgery: a nationwide population-based study in Denmark 2001-2011. Ann Surg Oncol. 2014;21(7):2267-2273.

20. Iversen LH, Norgaard M, Jacobsen J, Laurberg S, Sorensen HT. The impact of comorbidity on survival of Danish colorectal cancer patients from 1995 to 2006 - a population-based cohort study. Diseases Colon Rectum. 2009;52(1):71-78.

21. Danish Regions [homepage on the Internet]. Available from: http:// www.regioner.dk/in+english. Accessed January 3, 2016.

22. The Danish Clinical Registries (RKKP) [homepage on the Internet]. Available from: http://www.rkkp.dk/in-english/. Accessed January 3, 2016.

\section{Dovepress}

systematic reviews, risk \& safety of medical interventions, epidemiology \& biostatistical methods, and evaluation of guidelines, translational medicine, health policies \& economic evaluations. The manuscript management system is completely online and includes a very quick and fair peer-review system, which is all easy to use. 